\title{
Large-scale desalination: what can South Africa learn from Australia?
}

\author{
D. S. Bosman \\ Trans-Caledon Tunnel Authority, Centurion, South Africa
}

\begin{abstract}
The introduction of large-scale desalination to the South African water resource planning portfolio is imminent, and there are indications that such projects will be launched within the timeframe of five to ten years. The Trans-Caledon Tunnel Authority (TCTA) is positioned as a likely implementing agency, and is preparing for this role by studying the implementation experiences of similar projects abroad. Australia is well-suited as a benchmark, since it has undertaken six large-scale desalination projects since 2006, and the implementation experiences are still recent. Furthermore, the Australian projects were characterized by very high environmental requirements, a very comprehensive procurement approach, and achieved varying degrees of capital and operational efficiency.

This study and site visits covered four projects, in Brisbane, Adelaide and Perth (two) during June 2012. Project-specific learning included the basic principles of the alliance model of procurement, stakeholder management and public engagement, and the key importance of choosing an optimal site.

It is worth noting that, notwithstanding careful planning by the Australian authorities, a number of risks still materialized, and expensive lessons were learned during the procurement and implementation of the projects. The objective therefore, is to internalize these lessons prior to embarking on a similar undertaking.

Keywords: alliance model, Australia, large-scale desalination, lessons learned, site selection, value-for-money.
\end{abstract}




\section{Introduction}

The introduction of large-scale desalination to South Africa is imminent [1]. Sea water desalination, in particular, is widely recognised as an immensely scalable and climate-independent water resource, and has been adopted on a global scale. Global Water Intelligence (GWI) estimates that by 2012, around 74,800 million litres of desalinated water is being produced by more than 15,000 plants each day. The long-term growth trend, by volume, is estimated to be $12 \%$ (compound annual growth rate, or CAGR), which suggests that global water scarcity is growing faster than both the economy and the population [2].

In line with South Africa's National Desalination Strategy [3], which earmarks specific roles in financing and implementation of large-scale desalination projects, the Trans-Caledon Tunnel Authority (TCTA) has undertaken to build a knowledge hub in large-scale desalination. The aim is to scale up the capacity of the public water sector to implement such projects, when they become necessary. As the implementer of off-budget bulk water infrastructure in behalf of the South African Department of Water Affairs (DWA), TCTA is ideally placed to become an implementing agency for largescale desalination projects, or to provide guidance to water boards who undertake such projects on their own accord.

Desalination introduces a number of new disciplines and areas of technological expertise, which are not usually required in the construction of dams, weirs, pipelines or abstraction works, e.g. chemical process engineering, metallurgy, membrane technology, mechanical engineering, fluid dynamics, and others. Beyond the technical realm there are other new challenges as well, in terms of environmental and social impact, and these will be explored in the sections to follow.

It is therefore essential that the implementing agency be well-informed and knowledgeable on the technical aspects of the intended project, and be particularly astute in the procurement of a long-term alliance partner. A suboptimal choice of partner will have a long-term impact on project efficiencies. The notion that the implementing agency could be guided by consultants, or benignly learn at the expense of the chosen consortium as the project progresses, and so compensate for a lack of insight into desalination practices, is extremely risky.

Given that the intended learning was to focus on implementation issues, it was important to visit projects that were either underway, or had recently been completed; a mature facility may not have the retained corporate memory, to impart the lessons being sought. As a destination, Australia was an easy choice. Since 2006, it had initiated six major sea water desalination projects, and at the time of visit (June 2012), would present a range of newly completed or nearly completed projects. Furthermore, Australia has similar challenges to South Africa in terms of climate change, robust bulk water infrastructure, and prior to their desalination build programme, a high level of reliance upon surface water resources by the metropolitan hubs. 


\section{Some characteristics of the Australian desalination build programme}

The rainfall patterns on the Australian continent has been in a decline over the long term, and especially in the catchment areas that supply the surface water resources of major metropolitan hubs. Large areas in Queensland, New South Wales and Victoria have seen declines of average decadal precipitation of more than $50 \mathrm{~mm}$ over the period 1970 to 2008 [4]. This has eroded the reliability of surface water resources of a number of cities: Sydney, Melbourne, Brisbane and Adelaide.

Over a shorter time-span, Australia had endured significant hardship during the Millennium Drought (2003-2010), which was a key driver of the desalination build programme. Ironically, the drought was emphatically broken before many of the projects could be completed, which caused a shift in both public and political support for desalination in a number of the Australian states.

A notable characteristic of the Australian desalination build programme is that it produced the most expensive grouping of large Sea Water Reverse Osmosis (SWRO) plants built to date (see Figure 1). The Australian projects have been subjected to perhaps the toughest standards of environmental protection in the world. Intake and outfall structures were designed to minimise the impact on marine life and the surrounding environment, and this has resulted in very expensive marine civil works. The sludge from pre-treatment is typically dried and placed in a landfill, rather than returned to the sea. The plants were developed in tandem with renewable wind energy, to offset the carbon footprint. Plant architecture was often adapted to minimise environmental disruption, usually at great capital expense. Environmental compliance is probably the main reason why Australian desalination is so expensive.

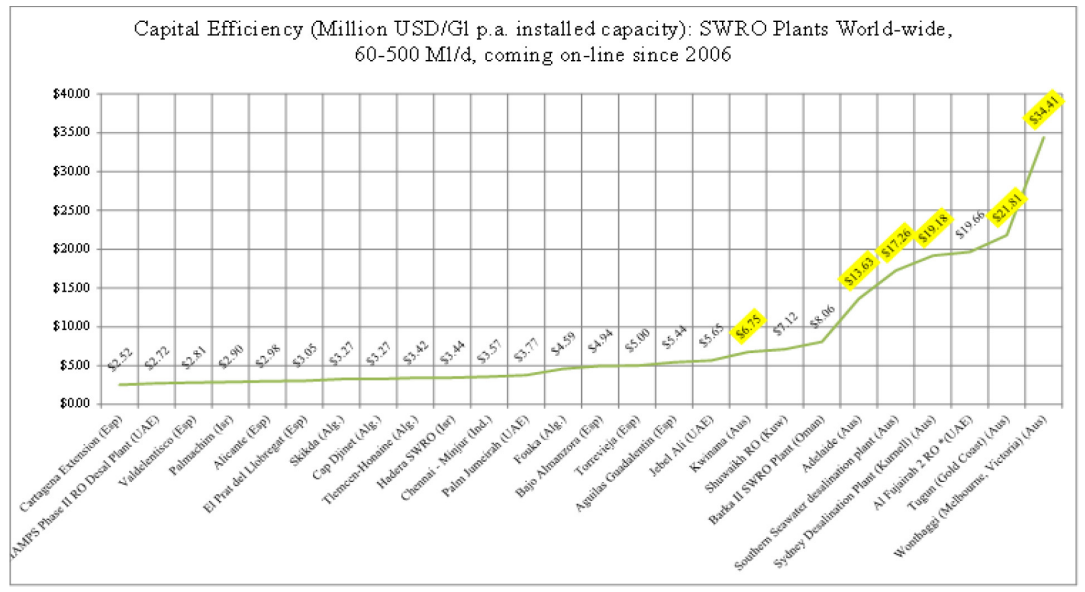

Figure 1: Comparing the capital efficiency of extra-large SWRO plants completed since 2006 [6]. 
Secondary reasons for the high cost of the Australian projects include the alliance procurement model, the unionised local labour force, and the risk premium that projects outside the Gulf market tend to attract, due to the absence of a track record of long-term successful projects [5].

In Figure 1, twenty-six comparable projects, all SWRO plants in the 60-500 million litres per day range and commissioned since 2006, are placed in order of descending capital efficiency. The measure for capital efficiency in this instance is the capital outlay, in millions of US Dollar, divided by the design capacity, in millions of litres per day. It can be seen that the Australian projects dominate the least capital efficient end of the spectrum. It is therefore clear that the Australian desalination build programme offers a vast arena for learning.

\section{Selected projects for study}

The study encompassed the desalination projects of three regional water utilities:

SeqWater in Brisbane, Queensland, owners of the Gold Coast Desalination Project, situated in Tugun.

SA Water in Adelaide, South Australia, owners of the Adelaide Desalination Project, situated in Port Stanvac.

Water Corporation in Perth, Western Australia, owners of the Perth Desalination Project situated in Kwinana, and of the Southern Desalination Project situated near Binningup.

\section{Key lessons learned}

The following insights emerged as "lessons learned" from the four projects visited and examined:

\subsection{Getting procurement right: the alliance model}

It was realised at an early stage that the conventional engineering, procurement and construction (EPC) approach, which had been the norm on numerous capital projects of the past, would not be appropriate in the procurement of a large-scale desalination plant. The technical complexity of desalination projects created too many opportunities within the EPC approach for contractors to bid low, secure the contract on a sub-economic level, but recover margins through project variances later. This practice had become common in both the Spanish and US water infrastructure sectors in recent years, with over-charging of up to $30 \%$ being witnessed [5].

The Australian projects have had favourable results from following an alliance approach in procurement, before entering into a Design-Build-OperateMaintain (DBOM) institutional model. The aim of the alliance approach is to create a project environment where the interests of both the client/agency and the contractor/consortium are aligned through smart incentives and risk-sharing arrangements. This procurement approach is designed to minimise the risk of cost over-runs. 


\subsubsection{Origins of the alliance model}

The "Alliance Model" of contracting is widely used by the Australian public infrastructure sector; by 2012, alliance contracts represented one third of the total value of public sector infrastructure projects delivered. The model has been formalised in the "National Alliance Contracting Policy and Guidelines," and came from a reform initiative by the Infrastructure Working Group of the Council of Australian Governments [7].

\subsubsection{The process of forming an alliance}

The alliance model follows a process during which prospective alliance partners are evaluated and eliminated from the bidding process, until only one remains. The alliance-forming process that resulted in the Multiplex-Degremont consortium being appointed to construct and operate the Kwinana desalination plant, serves as an example.

Water Corporation set out to fund the design and construction of the Kwinana desalination plant, whilst retaining ownership of the facility. It also wished to procure the most appropriate, long-term alliance partner who could do the design, construction, operations and maintenance aspects. Much of the evaluation was therefore focussed on the likelihood of a successful long-term relationship during the operations and maintenance (O\&M) phase.

The alliance development process comprises two main phases; The Registration of Interest (ROI) and the Project Development Phase (PDP). During the ROI phase, private sector companies are invited to submit their qualifications, proposed personnel and cost estimate for the project development phase (PDP). For the Kwinana project, nine applicants submitted offers, using separate technical and financial envelopes. After evaluation of the technical responses, the field of nine bidders was narrowed to five. Each of the five was then interviewed in interactive workshops, and the field was further narrowed to two, who were then selected as participants for the PDP-phase. Their financial bids were then opened to ensure that cost estimates were within a predetermined range.

On the Kwinana bid, two consortia went into the PDP phase. The PDP phase ran for $51 / 2$ months, during which time the Water Corporation seconded key personnel into each team. Weekly progress meetings and numerous workshops were held with each participant, which provided a continuous assessment vehicle for the client, and assist it in determining which participant provided the bestvalue outcome. The PDP phase produced two detailed, competing proposals in whose accuracy the client had a high degree of confidence. These proposals had the designs completed to about $30-40 \%$, all technical and financial risks identified, contained detailed capital and operating cost estimates, and had all risk and reward mechanisms negotiated. The latter two deliverables gave rise to a commercial framework, depicted in Figure 2, which contains the project Target Out-turn Cost (TOC), as well as the mechanism by which both the reward for outstanding performance, and the pain of poor performance, relative to the TOC, will be shared within the alliance. This commercial framework is also known as the "gain-share, pain-share" regime. 


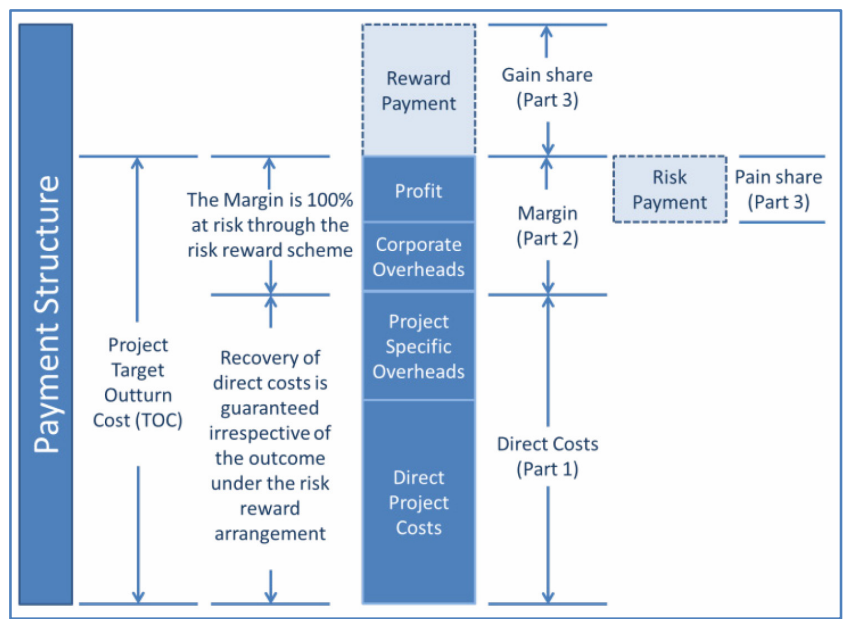

Figure 2: $\quad$ The Gain-share, pain-share regime of the Alliance Model [8].

In the final evaluation, the two proposals were evaluated using criteria that include life-cycle cost, culture, capability and commitment. Following a detailed commercial, technical and qualitative evaluation, one consortium was appointed as the alliance partner, and thereby chosen to design, construct, operate and maintain the plant in an alliance with the Water Corporation.

\subsubsection{Characteristics of the alliance model}

It is clear that the alliance model is a fundamental departure from traditional methods of procurement and contracting. One characteristic is that competition for the bid is extended quite far into project design. This is a costly and timeconsuming process, especially for the bidders, and adds to the overall project cost. At Kwinana, the Water Corporation reimbursed the losing bidder for its time and costs incurred.

Another characteristic is that all risks are shared equally within the alliance. The alliance project agreement includes a mechanism for the client to share any additional costs with the contractor; if there are savings, the initial benefit goes to the contractor, but after a certain level they are shared with the client. This promotes a "best-for-project" decision-making culture.

The project team comprise of people selected from contractor and client staff, again on a "best-for-project" basis. This creates an excellent platform for knowledge transfer. All decisions, behaviours and communications within the project team are based on preserving honesty and trust, with a full commitment to open communication and sharing of information. From the outset, a commitment is given by both parties to operate on a transparent, open book financial basis. As a result, all outcomes within the alliance are pursued to be either win-win or lose-lose, with no win-lose outcomes. Clearly, the alliance approach requires a very mature business environment. 


\subsection{Stakeholder management and public participation}

The importance of robust public participation and stakeholder management in the implementation of desalination projects cannot be over-emphasised. This requirement is even more acute when the site selected for construction is controversial; for example a previously undisturbed coastal site, or in a position where it may disturb a settlement or a natural habitat. Even if the statutory licensing for the plant could be obtained, public activism may require very costly environmental mitigation measures to be incorporated in the plant design and architecture.

A good programme of stakeholder management and public participation can be seen as the mechanism through which public concerns are channelled and responded to, and through which the project can engage the community, and impart the merits and factual basis of desalination. The following are the key lessons learned from the Australian projects in respect of stakeholder management and public participation, and should be considered when similar projects are undertaken in South Africa.

\subsubsection{Engage and consult with the affected communities from the outset}

An example from the most recent Australian project illustrates this point: The Southern Desalination Project was announced by the Premier of Western Australia on 15th May 2007. The first letter from Water Corporation addressed to the coastal communities of Binningup and Myalup, situated closest to the proposed site, is dated 23rd May. From the outset, the communities were presented with factual information as it unfolded, as well as contact details of the liaison officers, and were invited to a community meeting.

\subsubsection{Educate for a science-based debate}

The Adelaide Desalination Project serves as a good example: The plant has a substantial and very attractive interpretive centre, aimed at receiving educational touring parties from schools or universities. Here, the factual basis for the decision to establish the plant, inclusive of the environmental, economic and safety considerations is being conveyed to visitors. The aim is to keep the debate on the merits of desalination and the specific project on a science-based factual level; in its absence, the debate could easily degenerate into value-based arguments.

\subsubsection{Adopt a strategy for regular, clear communication}

Considering the good practices of both the Adelaide and Southern projects, it was the norm to implement a strategy of regular and clear communications with affected communities from the early days of the project. One component of the strategy would be a colourful and engaging monthly newsletter, containing regular updates and illustrations of project progress, news on community events sponsored by the project, advance notice when construction moves into a next phase, a description of the potential impacts, and invitations to local communities to participate in project events, where possible. The strategy would also entail a community liaison forum, with monthly meetings held on-site. 
Finally, the web was used extensively to disseminate project information and updates. Usually, the water utility would dedicate several detailed web pages on its corporate site to the project, with a facility to submit comments. Key documents relating to site selection, licensing and environmental impact would be available for download [9].

\subsubsection{Ensure transparency and responsiveness}

It is an imperative of a stakeholder management programme to be accessible for community inputs and submissions, to be transparent in all dealings, and to be responsive wherever possible. On the Southern project, these principles are clearly visible. Community liaison meetings were regularly held on the construction site, and stakeholders were periodically given tours of the site. When concerns were raised that aural and visual disturbances may affect the nearby community, the plant architecture and landscaping were amended at significant cost, to mitigate the effect. An 8 metre high berm was constructed to enclose the plant, and the plant architecture was lowered.

$\mathrm{Up}$ to 38 issues were addressed through an "Endorsed Commitments Register", which listed the commitments made by the project owners to stakeholders. Some of the commitments resulted in significant cost implications: One item committed to a tunnelling instead of trench design for the marine works, which has major cost implications.

Certainly, accommodating community concerns could not be open-ended, but the two Australian examples have illustrated that significant goodwill and buy-in from affected communities could be obtained by making concessions to reasonable requests, and by demonstrating a commitment to a sustainable, responsible implementation.

\subsection{Site selection}

Site selection involves the practice of locating a new facility; this involves quantifying the requirements of a new project, comparing it against the merits of potential locations, and selecting the site which performs best in the analysis. The selection of a site for a new, large-scale desalination plant contains a number of quite unique considerations, such as the characterisation of the sea water and off-shore currents, in addition to the more generic requirements.

Site selection is an extremely important decision-point in the design of the project, as the choice will be a key determinant of the efficiencies and risks that will characterise the plant over its entire lifespan. As a result, site selection is typically preceded by an in-depth investigation into the project requirements, and the degree to which alternative sites will address those needs. Costs and benefits of each site parameter are quantified, as well as the timeframe in which it will occur, and the Net Present Value (NPV) calculated. Allowing for key considerations that could not be quantified, the site with the lowest NPV would usually be selected.

In selecting the site for the Southern Desalination Project, Water Corporation (the implementing agency) identified Binningup as a potential site following extensive investigations of the coastal strip from Jurien Bay to Bunbury. The 
Binningup site was deemed the best location, based on a range of social, environmental, technical and economic factors. The plant would have minimal impact on environmentally sensitive areas, and had compatible surrounding landuses. The site was in close proximity to the sea, and was already owned by the implementing agency. The site exceeded the minimum size limit of 20 hectares, and had adequate buffers as required by the chlorination facilities. And finally, it allowed easy integration into the water supply network, and could access a suitable power source. A $133 \mathrm{Ml} /$ day SWRO plant requires a power supply of about 22 Megawatt, assuming a specific energy consumption of $4 \mathrm{kWh} / \mathrm{m}^{3}$ [10]. The above considerations should be supplemented by the following, which arose from the other projects reviewed.

\subsubsection{Site elevation}

The Port Stanvac site of the ADP is located on a coastal ledge 50 metres above sea level. Whereas this posed some challenges in the design of the marine abstraction works, resulting in a very deep pump chamber, and additional pumping costs, it does offer the benefit of protection of the plant against extreme tidal events (e.g. tidal surges and tsunamis).

\subsubsection{Comprehensive and extended period of sea water characterisation}

The quality of feed water has a profound impact on the treatment process design, and in particular on the pre-treatment design, and should be thoroughly studied over at least a year. This will have an impact on both the capital outlay, as well as operating costs. It is estimated that the unit cost of desalination of sea water from the South African West Coast could be $40 \%$ higher than that of the East Coast, due to higher organic content of the former [11].

\subsubsection{Prior utilisation of site}

A previously disturbed site can be attractive, as it often presents a lower environmental hurdle. The Binningup site had been used as a stone quarry before, and this eased some environmental concerns. The prior use of the site may also bring risks; the Tugun site had previously been a landfill; coupled with sub-standard civil works, it resulted in contaminated groundwater ingress into the intake and outlet shafts [12].

\subsubsection{Coastal access}

A potential site may not have clear access to the beach (the Tugun site has an airport and residential area between itself and the beach), or disturbance of the beach may be restricted due to environmental or social sensitivity. In these instances, the plant designers may be compelled to follow a tunnelling method for the intake and outlet pipes, which bears significant cost implications.

\subsubsection{Characterisation of off-shore currents}

The rapid dispersal of brine in sea water, as well as a slow flow-rate of feed water at the intake, are both key design objectives of the marine structures, due to environmental concerns. Whereas the intake flow-rate could largely be achieved by design, brine dispersal is very much reliant upon the sustained flow 
of off-shore currents. Some plants are more susceptible than others; the Kwinana plant is perhaps the most intensely monitored plant in the world, due to its location within the environmentally sensitive and relatively still Cockburn Sound. During 2008, the desalination plant had to be shut down twice, due to insufficient brine dispersal [13]. A site within a coastal area with restricted or inconsistent ocean currents could lead to permitting delays, onerous monitoring requirements and the enforcement of periodic plant shut-downs, all contributing to reduced operational efficiency.

\subsection{Achieving value for money}

A key outcome of the alliance contracting described in section 4.1 is to achieve an optimal economic outcome over the project lifespan. Two measures were employed to assess the economic outcome: Capital efficiency, which is the ratio of capital outlay over yield, measured in $\$$ million per Giga-litre of water produced per annum, and operational efficiency, which is the ratio of operating cost over yield, measured in $\$$ million per Giga-litre of water produced per annum.

Figure 1 demonstrated that the Australian projects were generally much less capital efficient than the comparable projects in Spain, the Middle East and elsewhere. However, within the Australian cohort, a wide range of capital and operational efficiencies were achieved, which indicates that some projects had still achieved much better economic results than others. Table 1 illustrates the benchmarks. It should be noted that in this instance, the source used Australian Dollars, instead of the US Dollar-based comparison used in Figure 1. However, the relative performance of the projects remains unaffected.

Table 1: $\quad$ Benchmarking capital and operational efficiency [14].

\begin{tabular}{|c|c|c|c|c|c|}
\hline & $\begin{array}{l}\text { Installed } \\
\text { Annual } \\
\text { Capacity }\end{array}$ & $\begin{array}{l}\text { Capital } \\
\text { Cost }\end{array}$ & $\begin{array}{l}\text { Capital } \\
\text { Efficiency }\end{array}$ & $\begin{array}{l}\text { Operating } \\
\text { cost per } \\
\text { annum }\end{array}$ & $\begin{array}{l}\text { Operating } \\
\text { Efficiency }\end{array}$ \\
\hline $\begin{array}{c}\text { Desalination } \\
\text { project: }\end{array}$ & $\mathrm{Gl} / \mathrm{a}$ & $\begin{array}{c}\text { AUD } \\
\text { million }\end{array}$ & $\begin{array}{c}\text { AUD million / } \\
\text { Gl/a }\end{array}$ & $\begin{array}{c}\text { AUD } \\
\text { million }\end{array}$ & $\begin{array}{c}\text { AUD million } \\
\text { / Gl/a }\end{array}$ \\
\hline Victorian & 146 & 5500 & 37.74 & 600 & 4.11 \\
\hline Gold Coast & 42 & 1200 & 28.66 & & \\
\hline Sydney & 84 & 1900 & 22.69 & 258 & 3.07 \\
\hline Southern & 47 & 955 & 20.36 & & \\
\hline Adelaide & 101 & 1824 & 18.15 & 129.9 & 1.29 \\
\hline
\end{tabular}

From Table 1 it is clear that the Victorian project is the least efficient, in terms of both capital and operations. The Gold Coast project and the Sydney project make up the middle ground, with the Southern and Adelaide projects closely grouped as the best performers. Whereas there are many factors that would contribute to a project's performance in this comparison, and would certainly warrant a more in-depth analysis, the following observations may explain some of the differences: 
The Victorian project is located on a site with very high levels of environmental sensitivity, which required extensive landscaping to cover the entire plant, even on the roofs, to mitigate the impact and obtain approval.

The Gold Coast project was beset with engineering and site-related challenges, probably more so than any of the other Australian projects.

The later projects (Southern and Adelaide, completed in 2012) appear to perform better than the earlier projects, which suggests that some learning had transferred between projects, which perhaps manifested in greater efficiency in procurement, site selection and technology choice. Membrane technology, energy recovery devices and pre-treatment process design, in particular, are attracting much research and development resources, and are areas of on-going efficiency gains. Some of these advancements were incorporated in the later projects, and may have been a factor in their better performance.

Benchmarking emphasises the importance of carefully considered project design, site selection, alliance partner selection and efficient execution.

\section{Conclusions}

The four Australian projects assessed in this study provided significant areas of learning, which will be invaluable to the South African water sector and the state agency tasked to implement the first similar project. Whereas the water demand and resource options in the three main coastal hubs will determine the timeframe of these developments, it is perhaps indicative that the Water Infrastructure Investment Framework recently prepared by the Government of South Africa [15] prioritised four such projects within the ten-year planning horizon.

In addition, local projects to reuse mine water or municipal wastewater will very likely emerge in the same timeframe, or even sooner. Given the similarities in technology and project design, many of the insights from the Australian sea water desalination projects could transfer to the reuse environment.

Finally, it is worth noting that even in the relatively robust institutional environment of Australia's federal and state governments, not all the challenges of the desalination build programme were anticipated, and some expensive lessons were learned, despite efforts to pre-empt them.

\section{Acknowledgements}

Introductions made by Borvin Kracman, the water lead of ARUP in Australia, proved to be invaluable in securing appointments with key project staff. We also thank the management and staff of the three water utilities who kindly hosted our visit to their projects, and who made time for in-depth discussions: Seqwater in Brisbane, Queensland, SAWater in Adelaide, South Australia, and Water Corporation in Perth, Western Australia. 


\section{References}

[1] Van Rooyen, J. Increasing competition for finite water resources: Options for the future. International Conference on Fresh Water Governance for Sustainable Development. Pretoria: Department of Water Affairs of South Africa, 2012.

[2] DesalData. Desalination market update (Presentation). The 25th IDA/GWI Worldwide Desalting Plant Inventory. IDA, 2012.

[3] DWA. National Desalination Strategy. Pretoria: Department of Water Affairs, 2011.

[4] Australian Government, Bureau of Meteorology. Australian climate variability \& change - Trend maps. Retrieved January 14, 2013, from http://www.bom.gov.au/cgi-bin/climate/change/trendmaps

[5] Gasson, C. (2012). Insight: It is time to count the real cost of public money? Retrieved January 21, 2013, from Global Water Intelligence: http://www.globalwaterintel.com/insight/it-time-count-real-cost-publicmoney.html

[6] DesalData. (n.d.). Analysis. Retrieved January 18, 2013, from DesalData.com: http://desaldata.com/projects/analysis

[7] Australian Government. (2012). National Alliance Contracting Policy and Guidelines. Retrieved January 21, 2013, from http://www.infrastructure. gov.au/infrastructure/nacg/index.aspx

[8] Water Corporation. Request for Proposals. RFP to form alliances to design and construct, and to operate and maintain the Southern Seawater Desalination Plant. Perth, Western Australia, Australia: Water Corporation, 2007.

[9] SA Water. Adelaide Desalination Project. Retrieved October 2012, from http://www.sawater.com.au/SAWater/WhatsNew/MajorProjects/ADP.htm

[10] Water Corporation. Second Seawater Desalination Plant, Site Alternatives and Considerations. Perth: Water Corporation, 2007.

[11] Offringa, G. An overview of brackish and sea water desalination for potable water supply. Centurion, Gauteng, South Africa, 2011.

[12] WaterSecure. Summary and Commentary on known non-compliance issues and level of compliance with the project brief. Brisbane: Queensland Government, Department of Infrastructure and Planning, 2009.

[13] Jennings, P. Is Desalination Sustainable? Western Australia Policy Forum, 2008.

[14] Kumar, M. Adelaide Desalination Project (Presentation). Adelaide, South Australia, Australia: SA Water, 2012.

[15] DWA. Water Sector Infrastructure and Investment Framework, Pretoria: Department of Water Affairs, 2012. 